\title{
Years Added to Life in Old Age
}

\author{
VÄINÖ KANNISTO, Ph.D. \\ Distinguished Research Scholar, \\ Max Planck Institute for Demographic Research, Rostock, Germany
}

\begin{abstract}
The momentous transition from high to low mortality - and thereby to modern society - has been thoroughly studied by measuring the dynamics of mortality by age and sex and by cause of death as well as by the ubiquitous summary measure, the life expectancy at birth. In the following, we look at it from a slightly different angle, the years added to different stages of life, particularly to old age.
\end{abstract}

\section{Material and method}

We have used official life tables issued in various countries and collected to a life table archive at the Max Planck Institute for Demographic Research in Rostock. We have used period life tables, not cohort tables, in order to observe the historical process.

We have simply observed the changes over time in the life table parameter Lx which indicates the years lived at each age by a number of newborn. The Lx column thus corresponds to the stationary population under given mortality conditions and does not reflect changes in the number of births. Increases in Lx values indicate years added to life while decreases indicate losses. Pronounced losses occur often at times of wars and epidemics but minor transitory losses were also observed in various countries in the 1960 s, particularly among middle-aged men.

\section{Years added to life in Finland in the 20th century}

The early stages of mortality transition which began in Finland towards the end of the 19th century, were marked, as elsewhere, by a gradual conquest of epidemic diseases, by an improvement in general hygiene and environmental sanitation which all resulted in sharp reductions in infant and child death rates together with more modest progress in adult age. 
Figure 1. Years added to life. Finland. By 5-years age group, per 1,000 live born and per annum.
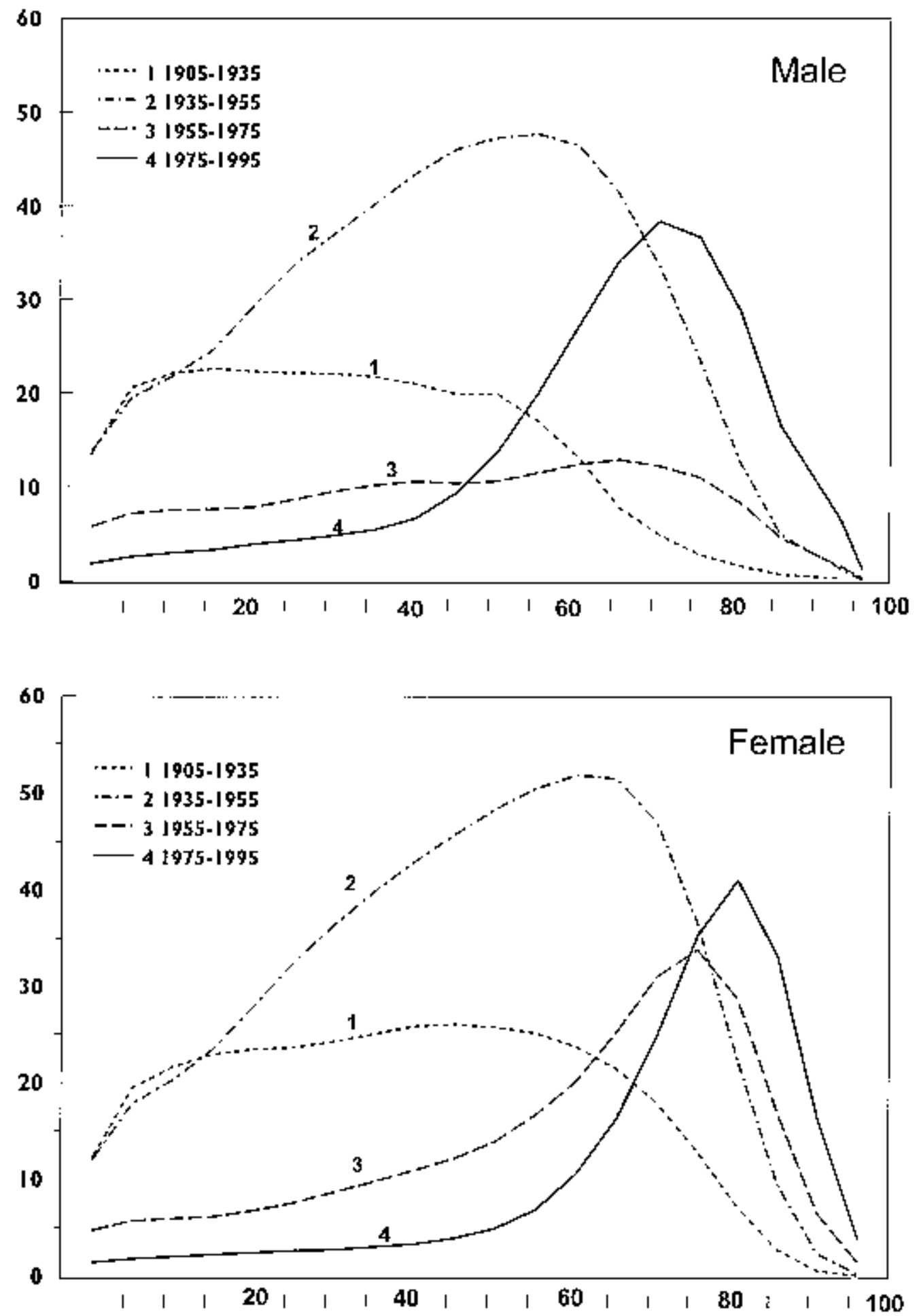
Shown in Figure 1, the gains in years lived were large from early childhood onwards as the persons saved from early death were able to live a full length of life, typical of the epoch. These gains were maintained and strengthened by further, though smaller, gains in later adult life. The curves of the period 1 in Figure 1 were therefore uniformly flat up to an age close to the modal length of life, which at those times was around 60-70 years. After this, the curves tapered off quite rapidly and this decline began for men at an earlier age than for women who made considerable gain in years lived even at the approach of old age. Altogether, the gains in lifeyears were not very rapid in this period but over several decades amounted to an epoch-making lengthening of human life.

Around 1960 this development accelerated brusquely, the main reason being the introduction of antibiotics, which had the effect of virtually eliminating pulmonary tuberculosis as a cause of death among young persons. They were also effective in controlling the communicable diseases of childhood and helped against many kinds of infections thus contributing to a lowering of death rates of middle-aged and even older persons. The curves of this period (period 2 in Figure 1) soared very high and reached their maxima around ages 60-65 after which they rapidly declined.

The upsurge in years lived soon run its course and was followed among men by stagnation or even a slight reversal, among women by a marked slowdown (period 3 in Figure 1). Although childhood mortality continued to decline to ever lower levels, it could not, for that very reason, any more produce great savings in lives. The years added to life had now a new configuration, much flatter for male than female, but the tapering-off of gains after the modal age remained essentially as before.

Soon later began an unprecedented decline in mortality at advanced ages, even at 80-100 years and, more discreetly, beyond. This resulted in great increases in years lived at high ages after around 1970 and affected soon all low-mortality countries, usually women a little earlier and stronger than men (Kannisto 1994: 44-45).

In Finland the change is manifest in Figure 1 from 1975 on. Men, for whom the progress had until then been slow, made large gains in late middle age: from age 55 or 60 onwards with a peak in the seventies and gradually less after that. Due to their already lower mortality, the gains for women were concentrated in the eighties, with an appreciable improvement even in the early nineties. A major increase in years lived in old age has thus taken place for both sexes since the 1970s. Closer to age 100, however, the gains have been small, if larger than ever before. 


\section{Years added to life at ages over 50 years: an international comparison}

After this general approach to the subject we shall focus on the increase in years lived in old age and accordingly limit the examination to ages over 50 years and to the period after 1950 when survival to old age became the prominent feature of mortality.

In his theory of epidemiological transition Omran defines this as the third stage and calls it the age of degenerative and man-made diseases (Omran 1971). It has been proposed to accept the later part of it as a separate stage, that of delayed degenerative diseases (Olshansky and Ault 1986). Robine would call the undivided third stage the age of the conquest of life duration, l'âge de la conquête de l'étendue de la vie (Robine 2000).

The post-1950 increase in lifetime after age 50 is shown in Figure 2 for three countries in the forefront of increasing longevity: Japan, France and Switzerland. The periods, renumbered, are now decennial and give thus a more detailed account of the transition. 
Figure 2. Years added to life in 5-year age groups per 1,000 live births and per annum.
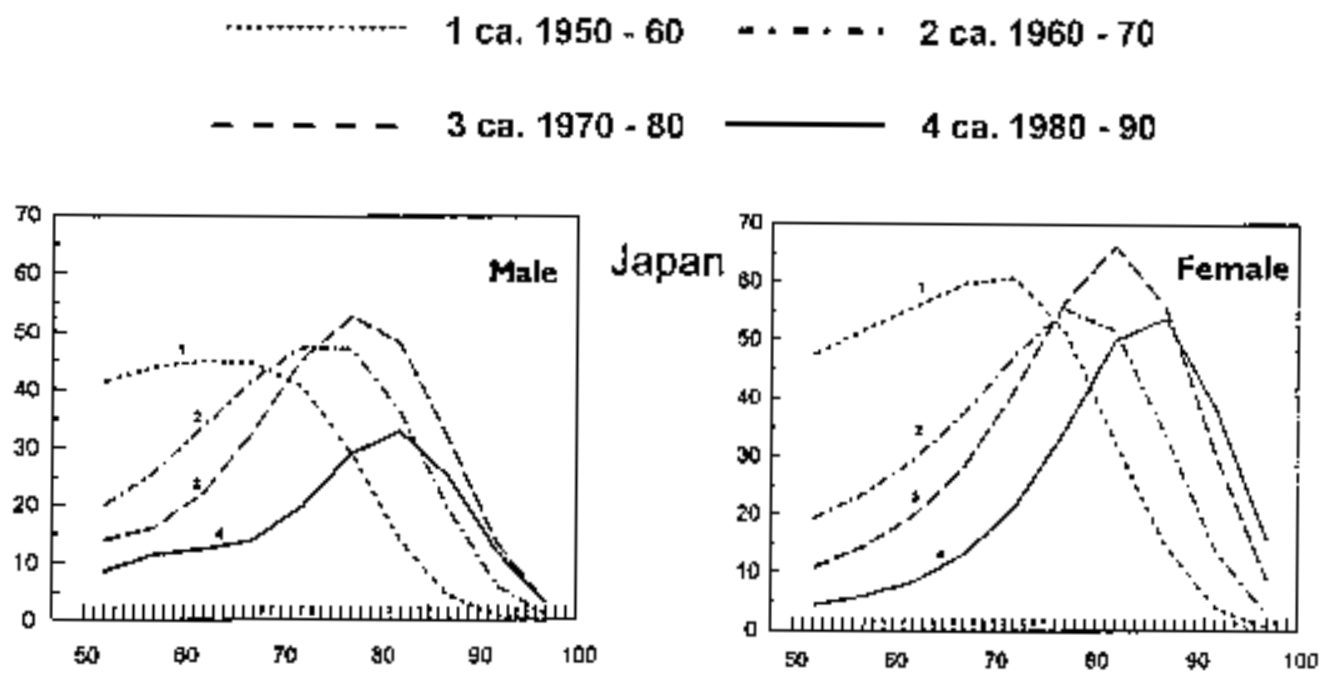

France
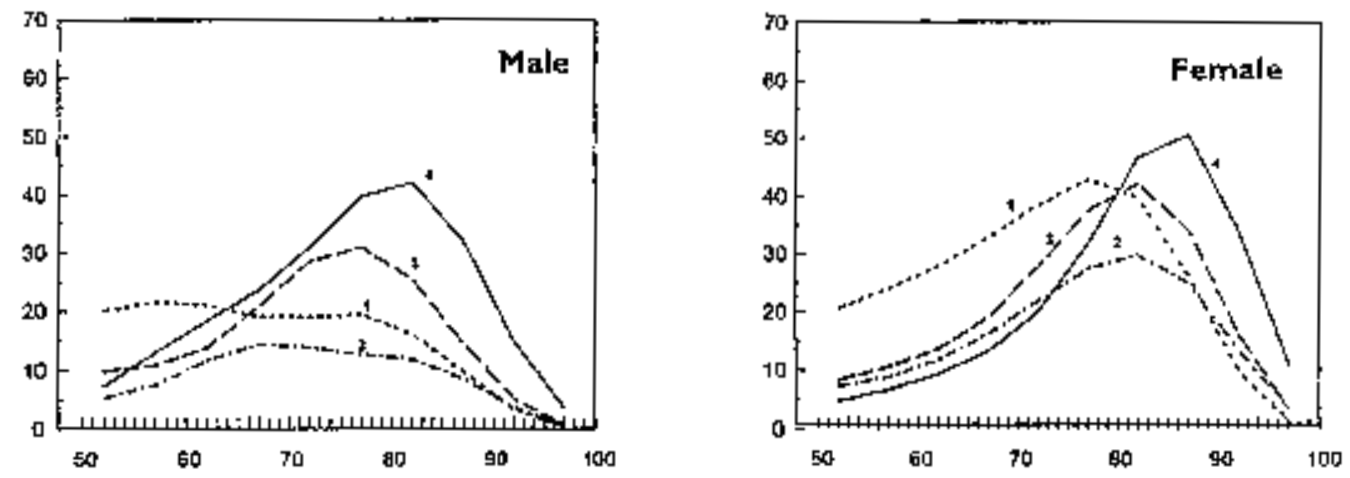

Switzerland
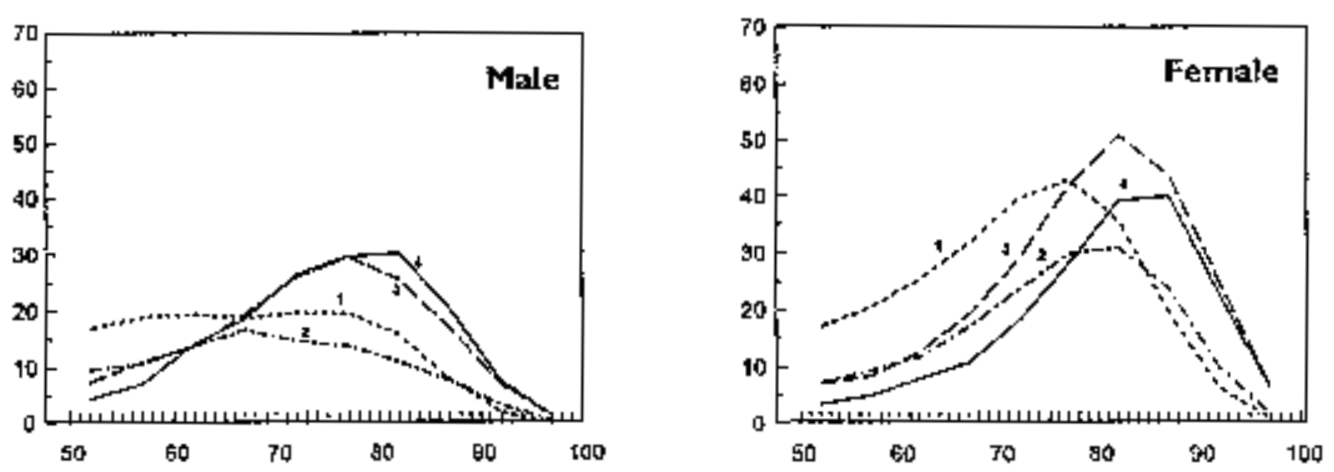
The pictures for males show certain differences between the three countries, the most striking being perhaps the high level of increase in the first period for middleaged men in Japan which is due to the fact that mortality decline there was still at early stages. In France and Switzerland death rates began to fall earlier but underwent a considerable slowdown in the second period. On the female side also, a certain slackening of the pace of progress is noticeable in the second period but the peak has moved each time to a higher age.

The overall picture is that of the gains moving consistently to higher ages and in the same process concentrating into narrower age ranges. The uniformly steep right hand slope of the peaks deserves attention because it testifies to increasing resistance of mortality to improvement close to the centenarian age.

The increase in the share of old age in years added to life is shown with greater precision in Table 1, which gives it in a few countries. In every country and period shown the percentage has been higher for females than males. This is to be expected because of the longer life expectancy of females but the size of the difference is perhaps a little surprising.

Table 1. Years added to ages 80 and over, percent of all years added to life.

\begin{tabular}{lccccc}
\hline Country & Sex & \multicolumn{4}{c}{ Approximate period } \\
\hline \multirow{2}{*}{ Japan } & & $\mathbf{1 9 5 5 - 6 5}$ & $\mathbf{1 9 6 5 - 7 5}$ & $\mathbf{1 9 7 5 - 8 5}$ & $\mathbf{1 9 8 5 - 9 5}$ \\
& $\mathrm{M}$ & 3 & 15 & 27 & 37 \\
France & $\mathrm{F}$ & 7 & 24 & 42 & 60 \\
& $\mathrm{M}$ & 10 & 17 & 21 & 36 \\
Switzerland & $\mathrm{F}$ & 19 & 33 & 37 & 56 \\
& $\mathrm{M}$ & 11 & 14 & 24 & 34 \\
Finland & $\mathrm{F}$ & 19 & 32 & 44 & 55 \\
& $\mathrm{M}$ & 5 & 13 & 15 & 25 \\
\multirow{5}{*}{ England } & $\mathrm{F}$ & 9 & 30 & 41 & 47 \\
& $\mathrm{M}$ & 10 & 15 & 15 & 27 \\
The Netherlands & $\mathrm{F}$ & 23 & 41 & 34 & 45 \\
& $\mathrm{M}$ & 14 & - & 14 & 19 \\
\multirow{2}{*}{ USA } & $\mathrm{F}$ & 28 & 41 & 50 & 47 \\
& $\mathrm{M}$ & - & 18 & 19 & 31 \\
\hline
\end{tabular}


In many countries, the share of old age has been increasing quite regularly for both sexes and particularly so in the three leading countries shown on top. An exception is the Netherlands where male mortality suffered a temporary setback. The series for the United States is also slightly irregular but leaves no doubt about the tendency to increasing relative weight of old age in years added to life. In spite of such irregularities in the decade-to-decade development, we observe a very strong fundamental tendency toward ever increasing gains for old age. In some countries, the share of ages over 80 is now more than one-half for females but hardly more than one-third for males.

This percentage in the share of old age is correlated with life expectancy at birth as shown in Figure 3 which gives these values in many countries over a long historical period. As long as the life expectancy at birth was less than 65 years, additions to ages over 80 were negligible. With growing life expectancy they began to increase rapidly and when that of females reached 80 years, about half of all years added to life have been lived in old age.

Figure 3. Life expectancy at birth and percent at ages $80+$ in years added to life. 16 countries, different periods.

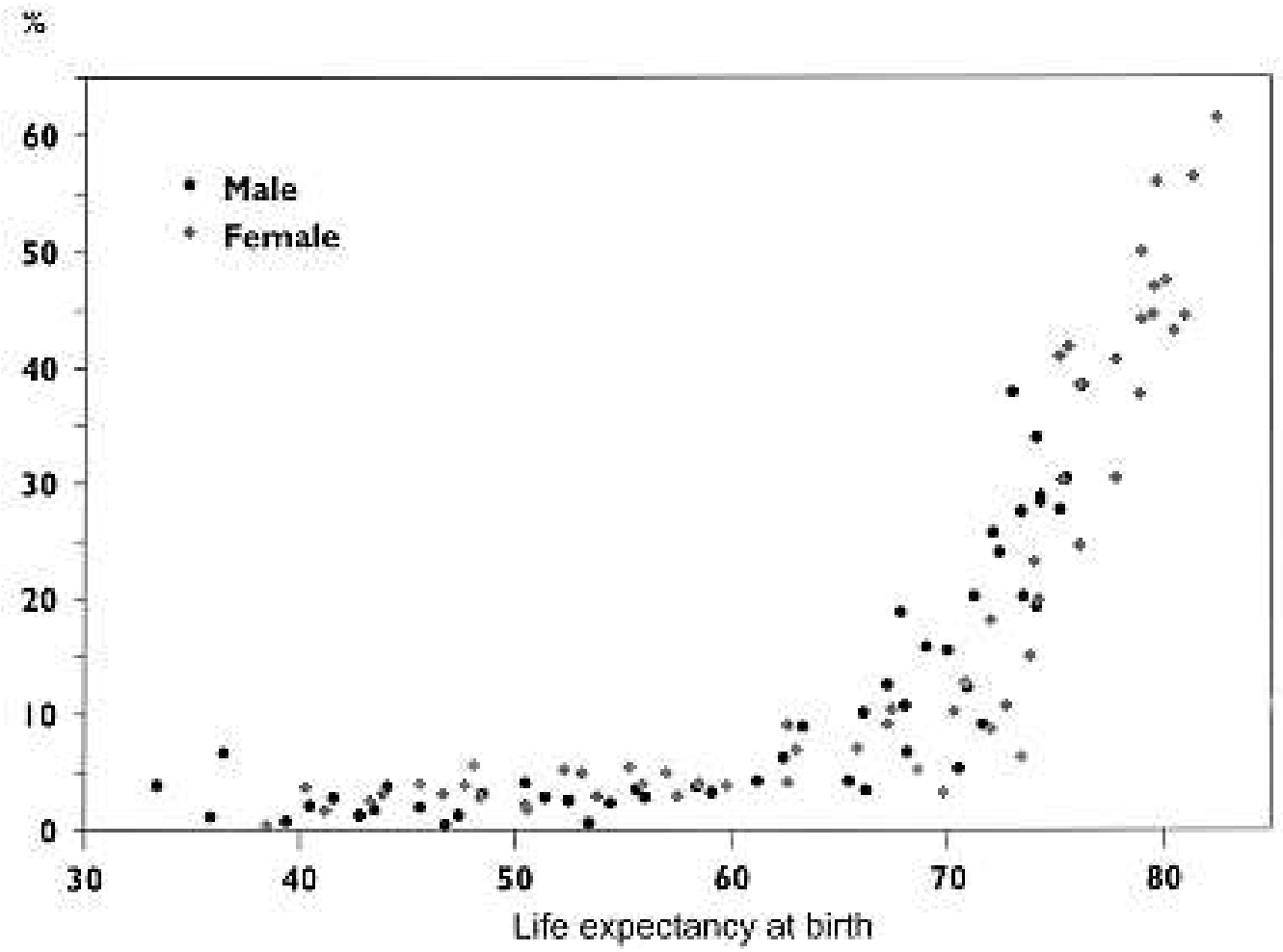


The proportion of ages over 80 among all years added to life is given for the most recent period on a wide front in Table 2. A look at the data confirms the dependence of the old percentage on the level of life expectancy at birth. This results in much lower values for developing countries. The percentage is regularly greater for females than males, often by a wide margin, India being the only exception.

Table 2. Years added to old age compared with life expectancy. In descending order of female percentage.

\begin{tabular}{llllll}
\hline Country & Period $^{1}$ & \multicolumn{2}{c}{ Percent of gain } & \multicolumn{2}{c}{ Life expectancy $^{2}$} \\
& & M & F & M & F \\
\hline Japan & $1988-93$ & 41.2 & 67.3 & 76.3 & 82.6 \\
France & $1988-93$ & 39.6 & 59.9 & 73.4 & 81.5 \\
Belgium & $1989-92$ & 37.9 & 56.0 & 73.0 & 79.8 \\
Switzerland & $1980-90$ & 34.0 & 55.8 & 74.2 & 81.1 \\
Sweden & $1988-93$ & 30.4 & 52.8 & 75.6 & 81.0 \\
Germany & $1993-96$ & 32.0 & 49.4 & 73.6 & 79.9 \\
The Netherlands & $1983-93$ & 19.3 & 47.5 & 74.1 & 80.2 \\
England & $1981-91$ & 27.5 & 45.0 & 73.4 & 79.0 \\
Australia & $1981-95$ & 27.7 & 44.5 & 75.2 & 81.0 \\
Finland & $1988-93$ & 21.5 & 43.3 & 72.1 & 79.7 \\
Italy & $1976-93$ & 26.0 & 43.2 & 74.1 & 80.5 \\
Austria & $1981-91$ & 24.0 & 41.7 & 72.5 & 79.0 \\
Ireland & $1981-91$ & 20.2 & 40.7 & 72.3 & 77.9 \\
Canada & $1976-81$ & 21.1 & 39.6 & 71.9 & 79.0 \\
New Zealand & $1976-86$ & 20.4 & 37.1 & 71.1 & 77.1 \\
USA & $1983-93$ & 31.1 & 37.0 & 72.1 & 79.0 \\
Scotland & $1981-91$ & 21.4 & 35.9 & 71.4 & 77.1 \\
Slovenia & $1981-91$ & 12.9 & 22.6 & 69.5 & 77.4 \\
Greece & $1961-80$ & 17.5 & 21.2 & 72.2 & 76.6 \\
Argentina & $1973-78$ & 11.0 & 18.3 & 65.4 & 72.1 \\
Mexico & $1970-80$ & 10.3 & 12.1 & 63.6 & 70.3 \\
Malaysia & $1970-80$ & 6.8 & 9.7 & 66.2 & 70.6 \\
India & $1955-80$ & 5.2 & 4.4 & 52.7 & 53.6 \\
\hline
\end{tabular}

1) Central years of successive life tables.

2) Years added to ages 80 and over, percent of all years gained.

3) At birth, in the later life table.

\section{Conclusions}

To know how large a part of life is lived at old age, or at any age, we have to observe the life table function $\mathrm{L}(\mathrm{x})$.

It is shown in this paper that during the long initial period of mortality transition, only minor gains were made to life in old age. Only when the reductions in mortality 
in childhood, youth and middle age were producing gradually diminishing returns, the share of old age in years of life gained began to increase noticeably, though at first quite modestly. It was only the unprecedented decline in old age death rates during the last two or three decades which began to lengthen substantially the life actually lived in old age.

According to the latest data, death rates at high ages still continue to decline in countries of low mortality, even though this decline is slower at ages around and above 100 years. The prospect is therefore good for further progress at least in the near and medium term. It is obviously of great importance to monitor the development closely, and the age distribution of years added to life should be part of it and it should go beyond the calculations of total additional lifetime which was the topic of this paper.

As more years are being lived in old age, the question arises of whether they are lived in good or ill health and with or without a handicap. Relevant survey activity towards this end is being carried out in many countries to measure healthy or disability-free life expectancy. For successful comparisons between populations or over time, it is essential to standardize the concepts and definitions (World Health Organization 1980), the classifications and even, as far as possible, the questionnaires. This activity is being coordinated by the agency REVES (Réseau Espérance de Vie en Santé) of the University of Montpellier (REVES 1993).

The results of a large number of studies carried out in many countries have established beyond doubt that healthy life expectancy has been increasing considerably, and there is at least tentative evidence that it has increased more than total life expectancy in which case the time lived in terminal ill health is shrinking, not expanding (e.g. Robine and Ritchie 1991; Valkonen et al. 1994; Cambois and Robine 1997).

The present study has been based on life tables, dealing with stationary populations, and studies of healthy life expectancy yield likewise life table values. When the calculations are applied to actual or projected populations with their changing size and age composition, they acquire new practical immediacy in the context of population policy.

Another urgent requirement in the emerging situation is to take the necessary policy decisions to provide health and social services to the rapidly increasing numbers of old people. To guide and monitor such policies, it is necessary to map the living arrangements and needs of old persons, whether institutionalized or not. Considerable survey activity to that effect is being carried out as exemplified by the extensive work of Grundy (e.g. Grundy and Glaser 1997; Grundy 2000). 
It may be fair to say that all such endeavors, ranging from purely demographic studies to practical policy measures, have received insufficient attention in the past while the recent acceleration in mortality transition has suddenly propelled them into the foreground turning them into matters of great concern which they are likely to remain in the foreseeable future.

\section{References}

Cambois, E. and J.M. Robine. 1997. Social inequalities in health expectancy. Paper presented at European Population Conference, 11-13 June 1997, Cracow.

Grundy, E. 2000. Marital status and family support of the oldest-old. Paper presented at Seminar on Human Longevity, 23-25 October 2000, Montpellier.

Grundy, E. and K. Glaser. 1997. Household dynamics in later life in England and Wales. Paper presented at European Population Conference, 11-13 June 1997, Cracow.

Kannisto, V. 1994. Development of oldest-old mortality, 1950-1990. Odense Monographs on Population Aging, 1. Odense University Press.

Olshansky, S.J. and B. Ault. 1986. The fourth stage of the epidemiologic transition: the age of delayed degenerative diseases. Milbank Memorial Fund Quarterly 64(3): 355-91.

Omran, AR. 1971. The epidemiologic transition. A theory of the epidemiology of population change. Milbank Memorial Fund Quarterly 49(4): 509-38.

REVES. 1993. Statistical World Yearbook "Health expectancy". Les éditions INSERM. Paris.

Robine, J.M. and K. Ritchie. 1991. Healthy life expectancy: evaluation of a new global indicator of change in population health. British Medical Journal 202:457-60.

Robine, J.M. 2000. Redéfinir les phases de la transition épidémiologicue à travers l'étude de la dispersion des durées de vie: le cas de France. Paper presented at Seminar on Human Longevity, 23-25 October 2000, Montpellier.

Valkonen, T, A.P. Sihvonen and E. Lahelma. 1994. Disability-free life expectancy by level of education in Finland. In: Advances in health expectancies, edited by C.D. Mathers, J. McCallum and J.M. Robine. Australian Institute of Health and Welfare, AGPS, Canberra.

World Health Organization. 1980. Classification of impairments, disabilities and handicaps. Geneva. 